\title{
Molecular identification of Sarcocystis funereus sp. nov. (Apicomplexa, Sarcocystidae) in offspring of Tengmalm's owls Aegolius funereus (Aves, Strigidae)
}

\section{Ondřej Máca}

Czech University of Life Sciences Prague

\section{Marek Kouba}

Czech University of Life Sciences Prague

\section{Erkki Korpimäki}

University of Turku

David González-Solís ( $\sim$ dgonzale@ecosur.mx )

El Colegio de la Frontera Sur

\section{Research Article}

Keywords: transmission of coccidia, vertebrates, voles, ICZN, LSIDs, nomenclatural acts

Posted Date: August 3rd, 2021

DOl: https://doi.org/10.21203/rs.3.rs-755552/v1

License: (c) (i) This work is licensed under a Creative Commons Attribution 4.0 International License.

Read Full License 


\section{Molecular identification of Sarcocystis funereus sp. nov. (Apicomplexa,}

2 Sarcocystidae) in offspring of Tengmalm's owls Aegolius funereus (Aves,

3 Strigidae)

4

Ondřej Máca ${ }^{1,2}$, Marek Kouba ${ }^{3}$, Erkki Korpimäki ${ }^{4} \&$ David González-Solís ${ }^{5^{*}}$

${ }^{1}$ Department of Pathology and Parasitology, State Veterinary Institute Prague, Prague, Czech

Republic

$9 \quad{ }^{2}$ Department of Zoology and Fisheries, Faculty of Agrobiology, Food and Natural Resources, Czech 10 University of Life Sciences Prague, Prague, Czech Republic

$11{ }^{3}$ Department of Ethology and Companion Animal Science, Faculty of Agrobiology, Food and

12 Natural Resources, Czech University of Life Sciences Prague, Prague, Czech Republic

$13{ }^{4}$ Section of Ecology, Department of Biology, University of Turku, Turku, Finland

$145^{*}$ El Colegio de la Frontera Sur, Chetumal, Quintana Roo, Mexico (email: dgonzale@ecosur.mx

\section{Abstract}

The spectrum of species of Sarcocystis in birds and the role of the latter in the transmission of coccidia are still incomplete for many avian species including Tengmalm's owl Aegolius funereus (Linnaeus, 1758). Therefore, this study is focused on the morphological and molecular description of a new Sarcocystis species found in the intestine of the Tengmalm's owl and its possible role as definitive host. Ten fledgling owls from the Kauhava region of west-central Finland were parasitized by numerous sporocysts and oocysts in the intestinal mucosa scrapings (prevalence $100 \%)$. Sporulated oocysts and sporocysts measured $16.34-16.96 \times 11.47-12.09 \mu \mathrm{m}$ and $11.85-13.52 \times 7.77-9.25 \mu \mathrm{m}$, respectively. Skeletal and heart muscles were negative for sarcocysts. 
Linnaeus, 1758) from the Czech Republic. This is the first and most comprehensive record on Sarcocystis from owls obtained in Finland, thus highlighting the importance of molecular data in the species identification.

\section{Introduction}

Cyst-forming coccidia parasites of the genus Sarcocystis Lankester, 1882 can infect a wide variety of vertebrates, including birds, which could act as definitive and intermediate hosts in the life cycle of these parasites. However, the spectrum of species of Sarcocystis in birds and the role of the latter in the transmission of coccidia are still incomplete for many avian species including Tengmalm's owl Aegolius funereus (Linnaeus, 1758). This species is a small nocturnal cavity-nesting owl living in coniferous forests in the boreal zone and in alpine forests further south in the Holarctic region ${ }^{1,2}$. It feeds mainly on small mammals, among which voles of the genera Myodes Pallas, 1779 (= Clethrionomys Tilesius, 1850) and Microtus Schrank, 1798 are their main preys, while shrews of the genus Sorex and small forest birds are their most important alternative prey items ${ }^{3,4,5}$.

To date, relatively few studies have been conducted with the Sarcocystis species in A. funereus in wild; in fact, only Wiesner ${ }^{6}$, in a scientific meeting, reported sporocysts of Sarcocystis sp. in the Tengmalm's owl, which were experimentally developed in the bank vole Myodes glareolus (= Clethrionomys glareolus) Schreber, 1780. Whereas Zuo et al. ${ }^{7}$ and Zuo and Yang ${ }^{8}$ were unsuccessful in experimentally infecting A. funereus with Sarcocystis sinensis Zuo, Zhang et Yie, 1990 from China.

During radio-telemetry research of Tengmalm's owls in Finland, where decreasing densities of main prey (voles) occurred, some fledglings were found dead and subsequently parasitologically examined. Since this owl species has practically no records of species of Sarcocystis and the role of owl in the life cycle of parasite is partially known, this study is focused on the morphological and 
52

53

54

55

56

57

58

59

60

61

62

63

64

65

66

67

68

69

70

71

72

73

74

75

76

77 3 5

molecular description of a new Sarcocystis species found in the intestine of the Tengmalm's owl and its possible role as definitive host.

\section{Results}

All intestinal samples of the 11 owls examined under light microscopy were positive to oocysts and sporocysts of Sarcocystis, whereas samples of muscular tissues were negative.

\section{Nomenclatural acts}

This published work and the nomenclatural acts it contains have been registered in ZooBank, the online registration system for the ICZN. The ZooBank Life Science Identifiers (LSIDs) can be resolved and the associated information viewed through any standard web browser by appending the LSID to the prefix "http:/zoobank.org/". The LSID for this publication is:.....

Oocysts/sporocysts were described as follows:

Family Sarcocystidae Poche, 1913

Sarcocystis funereus sp. nov. (Fig. 1)

Description: thin-walled sporulated oocysts (Fig. 1a), 16.34-16.96 $\times 11.47-12.09(n=5)$ and sporocysts (Fig. 1b) were 11.85-13.52 × 7.77-9.25 (n=35).

Taxonomy summary

2 Definitive host: Tengmalm's owl Aegolius funereus Linnaeus, 1758 (Strigiformes: Strigidae).

4 Intermediate host: Unknown.

Distribution: Kauhava region, west-central Finland (approx. $63^{\circ} \mathrm{N}, 23^{\circ} \mathrm{E}$ ). 
Site of infection: Small intestine.

Deposited material: Symbiotype (oocysts/sporocysts in $2.5 \%$ potassium dichromate), and genomic DNA in Eppendorf tube were stored at SVI Prague. GenBank sequences MW349706 (18S rRNA gene), MW349707 (28S rRNA gene), MW373964 (ITS1 region), MW489293 (cox1 gene).

Etymology: The specific epithet is derived from the species name of its definitive host, i.e., funereus.

Genetic sequences of 20 Sarcocystis isolates (11 birds) were obtained for the $18 S$ rRNA, $28 S$ rRNA, ITS1 and cox1 loci, of which those of six owls were clearly identified as $S$. funereus sp. nov., while those from four and one owls were excluded due to their low quality/short fragments of sequences or failed in amplifying, respectively. All obtained $18 S$ rRNA sequences were identical; therefore, only one of 1773 bp was submitted to GenBank (MW349706). It shared a 99.69\% similarity with an Sarcocystis sp. isolate 5 (as named in GenBank) (1594 bp) (AF513487) from the European shrew (Sorex araneus Linnaeus, 1758) from the Czech Republic, 99.61\% with S. strixi Verma, von Dohlen, Mowery, Scott, Cerqueira-Cézar, Rosenthal, Dubey et Lindsay, 2017 (MF162315) in the barred owl (Strix varia Barton, 1799) from USA, and 99.55\% with S. corvusi Prakas, Kutkiené, Butkauskas, Sruoga et Žalakevičius, 2013 (JN256117) in the jackdaw (Corvus monedula [Linnaeus, 1758]) from Lithuania, S. halieti Gjerde, Vikøren et Hamnes, 2018 (MH130211, MF946587) in the great cormorant (Phalacrocorax carbo [Linnaeus, 1758]) from Lithuania, and the white-tailed sea eagle (Haliaeetus albicilla [Linnaeus, 1758]) from Norway. The representative $28 S$ rRNA sequence (MW349707) was 1509 bp and shared 97.59\% genetic similarity with S. strixi (MF162316) and S. lari Prakas, Kutkiené, Butkaukas, Sruoga et Žalakevičius, 2014 (MF946611) in the white-tailed sea eagle from Norway, whereas it shared 97.49\% similarity with S. lutrae Gjerde et Josefsen, 2015 (KM657771) in the Eurasian otter (Lutra lutra [Linnaeus, 1758]) from Norway. Analyses of the 
104

105

106

107

108

109

110

113

114

115

116

117

118

119

120

121

122

123

124

125

126

127

128

129

cox1 gene sequences (MW489293, 1060 bp) showed a high similarity (99.52\%) with S. strixi

(MF162317), 99.43\% with S. lutrae (KM657808) and 99.42\% with S. lari (MF596283, MF946584)

from the great black-backed gull (Larus marinus [Linnaeus, 1758]) from Lithuania and the whitetailed sea eagle from Norway. Representative nucleotide ITS1 region sequence was 1294 bp

(MW373964), with no significant match to other Sarcocystis species from GenBank, except 89.57\% similar (44\% query cover) to $S$. halieti (MF946596) and $89.52 \%$ similar (35\% query cover) to $S$.

lutrae (MG372109) in L. lutra from the Czech Republic. Single cases of double peaks were noted at $28 S$ rRNA at nucleotide positions 666,667 (TT/CC), while some ITS1 sequences differed only by one single nucleotide polymorphism (T/C) at nucleotide position 466.

The phylogenetic trees showed different topologies and relationships between the new species with its congeners according to the availability of sequences. Phylogenetic trees based on $18 S$ rRNA, $28 S$ rRNA and coxl genes showed a clade formed by the new species and $S$. strixi, as well as Sarcocystis sp. 5 (in the case of $18 S$ rRNA) (Fig. 2a, b, d), while tree of ITS1 region showed $S$. funereus sp. nov. in a single clade since the ITS1 sequence of $S$. strixi was not available, although the new species formed a group with other Sarcocystis spp. (Fig. 2c).

\section{Discussion}

The first published finding and description of the oocysts/sporocysts of Sarcocystis sp. in the Tengmalm's owl was made by Wiesner ${ }^{6}$ in Europe. Other Sarcocystis using owls as definitive hosts are: S. espinosai (Espinosa, Sterner, Blixt et Cawthorn, 1988) Odening, 1997 in the northern sawwhet owl Aegolius acadicus (Gmelin, 1788) from the USA ${ }^{9} ;$ S. dispersa Černá et Sénaud, 1977 in the long-eared owl Asio otus (Linnaeus, 1758), barn owl Tyto alba (Scopoli, 1769), masked owl T. novaehollandiae (Stephens, 1826) and Ninox novaeseelandie (Gmelin, 1788) in the Czech Republic and Australia ${ }^{10,11,12,13,14}$; S. rauschorum Cawthorn, Gajadhar et Brooks, 1984 in the snowy owl Bubo scandiacus (reported as Nyctea scandiaca) (Linnaeus, 1758) from Canada ${ }^{14}$; S. scotti Levine 
et Tadros, 1980 (this species is considered invalid ${ }^{15}$ ) and S. sebeki (Tadros et Laarman, 1976)

131 Levine, 1978 both in the tawny owl Strix aluco Linnaeus, 1758 from Europe ${ }^{16,17}$; and S. strixi in the

132 barred owl Strix varia from USA ${ }^{18}$. Hoberg et al. ${ }^{19}$ reported a coccidian (resembling Frenkelia or

133 Sarcocystis) in the northern spotted owl Strix occidentalis caurina Xantus de Vesey, 1860 from the

134 USA, although the proper identity of the parasite was undetermined. There also are reports of owls

135 acting as intermediate hosts for S. falcatula Stiles, 1983 in the great-horned owl Bubo virginianus

136 (Gmelin, 1788) from the USA ${ }^{20}$ and S. otus Krone, Rudolphi et Jakob, 2000 (invalid species

137 according to ${ }^{15}$ ) in As. otus from Germany ${ }^{21}$. Most of these were solely morphologically studied,

138 while only sporocysts of $S$. dispersa in Tyto alba (18S rRNA) ${ }^{22}$ and $S$. strixi $(18 S$ rRNA, $28 S$ rRNA

139 and $\operatorname{cox} 1)^{18}$ were morphological and molecularly characterized.

140

141 The size of fully sporulated sporocysts of Sarcocystis espinosai, S. rauschorum, S. sebeki and S.

142 strixi are within the range for those of the new species $(9.5-14.0 \times 8.0-12.0 \mu \mathrm{m}, 9.6-14.0 \times$

$143 \quad 7.0-10.0 \mu \mathrm{m}$ and $11.2-13.7 \times 8.8-10.9 \mu \mathrm{m}$ vs $11.85-13.52 \times 7.77-9.25 \mu \mathrm{m})$, and partially with the

144 sporocysts and oocysts of Sarcocystis sp. in S. o. caurina, S. dispersa and S. sebeki (11.0-12.0×

$145 \quad 5.0-6.0 \mu \mathrm{m}, 11-14 \times 8-11 \mu \mathrm{m}$ and $10.0 \times 14.0 \mu \mathrm{m}$ vs $11.85-13.52 \times 7.77-9.25 \mu \mathrm{m} ; 12.4-15.5 \times$

$1469.3-12.4$ and $17-20 \times 10-13 \mu \mathrm{m}$ vs $16.34-16.96 \times 11.47-12.09)$. Since the morphological

147 parameters of oocysts/sporocysts are insufficient to distinguish species, the comparison of these

148 Sarcocystis with the new species is unreliable. The sporocysts and oocysts of Sarcocystis sp. of

149 Wiesner ${ }^{6}$ were not described, so it is impossible to say if it belongs to $S$. funereus sp. nov., although

150 they could be conspecific.

151

152 On the other hand, of those species molecularly characterized, as $S$. dispersa (18S rRNA) and $S$.

153 strixi (18S rRNA, $28 S$ rRNA and cox 1 ), the first formed a different clade than that of $S$. funereus sp.

154 nov., while the second grouped together with the new species in the three genes. Apparently, $S$.

155 strixi and Sarcocystis sp. 5 are closely related (sister) to $S$. funereus sp. nov., but with genetic 
differences to be still considered as separated species. The ITS1 region is more sensitive to the

157 genetic differences among Sarcocystis species ( $\operatorname{see}^{23,24,25}$ ), while the $18 S$ rRNA gene is now

158 considered of limited taxonomic help ${ }^{15}$. Unfortunately, ITS1 region was not used previously in $S$.

159 dispersa nor S. strixi, thus making their comparison with the new species limited. This is the first

160 time that the ITS1 region was sequenced for a Sarcocystis from owls as definitive hosts and clearly

161 revealed the differences among species.

162

163 The intermediate host of $S$. funereus sp. nov. is unknown, but apparently rodents (different species

164 of mice and voles inhabiting the study area) $\left(\mathrm{se}^{4,26}\right)$ play that important role. Experimentally,

165 Wiesner ${ }^{6}$ observed that the bank vole $M$. glareolus acts as intermediate host and it could also be the 166 potential host for the new species, while the northern saw-whet owl A. acadicus, a congeneric owl

167 species from the USA, used the deer mice (Peromyscus maniculatus) $\left(\right.$ see $^{9}$ ). According to Mikkola ${ }^{1}$,

168 König and $\mathrm{Weick}^{2}$, there are more than 47 mammalian and 66 bird species used as preys by owls in

169 Europe, which could act as intermediate hosts for $S$. funereus sp. nov. The most common small

170 mammals used as prey by the Tengmalm's owl are the bank vole, field vole (Microtus agrestis

171 [Linnaeus, 1761]), sibling vole (Microtus levis [syn. M. rossiaemeridionalis] Miller, 1908) and

172 harvest mouse (Micromys minutus [Pallas, 1771]); less commonly are shrews (genus Sorex) ${ }^{4,26}$. In

173 the study area, the main preys of fledglings and adult Tengmalm's owls are bank voles, field voles

174 and sibling voles, whose abundances regularly fluctuate in high-amplitude (100-200-fold) three-

175 year cycle $27,28,29,30$. Accordingly, the abundances of individual vole species vary strongly. The

176 overall prey abundance could be $0.2-13.1$ and $0.6-28.2$ vole individuals per 100 trap-nights as

177 revealed by regular long-term snap-trapping in the study area during spring and autumn,

178 respectively, thus differing up to 65-fold times between different years/phases of the vole

179 cycle $^{4,29,31}$.

180 
181 It has been mentioned that species of Sarcocystis are more specific to their intermediate than

182 definitive hosts, especially those using rodents as intermediate hosts $\left(\mathrm{see}^{15}\right)$. In the case of $M$.

183 glareolus, it has been found as intermediate host of several types and unnamed species of

184 Sarcocystis from the Czech Republic ${ }^{32}$, Baltic region ${ }^{33}$ and Lithuania ${ }^{34}$, as well as of $S$.

185 clethrionomyelaphis Matuschka, 1986 in Germany, which uses canids, mustelids, snakes or birds of

186 prey as definitive hosts $\left(\mathrm{se}^{35,36}\right)$. One of the forms from Lithuania showed similar features (dense

187 hair-like projections on cyst wall) than that of Sarcocystis sp. described by Wiesner ${ }^{6}\left(\mathrm{see}^{34}\right)$, thus

188 corroborating the role of bank vole in the life cycle of the parasite. In the present case, even though

189 the intermediate host is unknown, the molecular analysis indeed determined that the developmental

190 stages in the definitive host belong to a new species, as herein stated.

191

192 The cause of death of Tengmalm's owls was undetermined, but the occurrence of Sarcocystis in

193 these birds should be monitored, since other taxa of this genus (S. falcatula, Sarcocystis sp. isolate

194 from chicken) have been reported as causing encephalitis in free-ranging great owls (B. virginianus)

195 and meningoencephalitis in chickens, respectively $\left(\operatorname{see}^{20,37}\right)$.

196

197 In the last decades, the integrative taxonomy by using morphological features and molecular

198 analysis has uncovered the huge diversity of species in various groups of organisms, including

199 protists $^{15}$. Additionally, it particularly improved the recognition of the specificity of Sarcocystis in

200 their intermediate and definitive hosts around the world. Apparently, S. funereus sp. nov. is specific

201 to A. funereus, which acted as natural definitive host of this parasite, thus representing the first host

202 record in A. funereus and the nineth owl species with a Sarcocystis species. Interestingly, the

203 Tengmalm's owl was experimentally infected with $S$. sinensis, but sporocysts and oocysts were no

204 found after some days of infection $\left(\sec ^{8}\right)$; this could indicate the host specificity of the new species.

205 However, birds of prey might be infected by more than one Sarcocystis species, as S. halieti and $S$. 
lari in the white-tailed sea eagle (H. albicilla) $\left(\mathrm{see}^{38}\right)$; therefore, more Tengmalm's owls, other owl species and birds of prey should be examined to determine the presence of other species or forms.

Tengmalm's owls are nomadic and the natal dispersal movements of those juveniles hatched in Finland could extend more than $1000 \mathrm{~km}^{39,40}$, while adult females show long distance breeding dispersal up to $>600 \mathrm{~km}$ in Finland ${ }^{4,39}$ and adult males are usually resident after their first breeding attempt ${ }^{4}$. They can also move over long distances and are widely distributed in North and Central Europe including the Italian Alps and Pyrenees in North Spain ${ }^{1}$. Therefore, it is highly probable that Tengmalm's owls could spread S. funereus sp. nov. out of Finland to various other locations within their distribution range. For instance, during a long-term study of Tengmalm's owl in the Czech Republic (years 2010-12 and 2015) a prevalence of 40\% was found for a Sarcocystis sp. in 10 fledglings ${ }^{41,42}$. Thus, these parasites seem to be present in that country, although the species identification should be confirmed to determine the real distribution of $S$. funereus sp. nov. However, Svobodová ${ }^{43}$ examined two Tengmalm's owls in the Czech Republic, which were negative to the presence of oocysts/sporocysts of Sarcocystis.

If we considered that family Strigidae comprises 223 species of owls reported around the world, more studies are needed to elucidate the parasite fauna and involvement of these birds in the life cycles of parasites. Thus, new findings will help in increasing the knowledge about this interesting group of predators, as well as their role as predators of rodents, which also act as intermediate hosts of several Sarcocystis.

This work provided the first and the most comprehensive record on Sarcocystis from owls in Finland, thus highlighting the importance of molecular data in the species identification. It also contributes to the better understanding of species diversity and current taxonomic status of the new species within the genus Sarcocystis. Further works including examinations of owl populations and 
232 particularly their preys in Finland, the Czech Republic and worldwide are required to elucidate the

233 life cycle of the parasite.

234

\section{Materials and methods}

236 The carcasses of 11 specimens (29-47 days old from hatching, 98-136 $\mathrm{g}$ in weight) from 7

237 different nests (10 died due to starvation and infection, 1 per marten Martes martes Linnaeus, 1758

238 predation) (MK and EK unpublished data) were examined in this study. They were collected in the

239 Kauhava region of west-central Finland $\left(63^{\circ} \mathrm{N}, 23^{\circ} \mathrm{E}\right)$ during a radio-tracking study of Tengmalm's

240 owl fledglings during the post-fledging dependence period in 2019. The study area is located

$24130-120 \mathrm{~m}$ above sea level and mostly covered by forest (for detailed description of the study area

$\left.242 \mathrm{see}^{4,31,44}\right)$. Aerial distances $(\mathrm{n}=21)$ between involved nest boxes from which the fledglings

243 originated and later subjected to necropsy were $19.2 \pm 9.3 \mathrm{~km}$ on average (range $3.8-38.7 \mathrm{~km}$ ).

244 Necropsies were carried out in the State Veterinary Institute (SVI) Prague, Czech Republic, where

245 the intestinal content and muscular samples (breast, legs, heart) of thawed birds were

246 parasitologically examined in wet mouth using water or glycerine for orientation purposes. After

247 parasite finding, intestinal mucosa scrapings were used for flotation-centrifugation coprological

248 method under light microscopy for the final evaluation and presence of oocysts/sporocysts using a

249 Leica DMLB optical microscope with a Leica DFC420 digital camera (Leica Microsystems,

250 Wetzlar, Germany), and isolation to Eppendorf tubes for DNA extraction. All measurements are

251 given in micrometres, unless otherwise mentioned.

252

253 Genomic DNA was extracted by glass bead disruption from 22 isolates (two from each owl) of 254 oocysts/sporocysts using the QIAamp ${ }^{\circledR}$ Fast DNA Stool Mini Kit (Qiagen, Hilden, Germany)

255 according to the manufacturer's recommendations. DNA was stored at $-20{ }^{\circ} \mathrm{C}$ until further use.

256 Polymerase chain reaction (PCR) and nested-PCR were carried out by using primers for $18 S$ rRNA

257 (ERIB1/A2R, A1F/S2r, A2F/Primer BSarc and Fext/Rext, Fint/Rint, respectively) ${ }^{38,45,46,47,48}$, 
$28 S$ rRNA (KL_P1R/KL_P1F $)^{49}$, ITS1 region (ITS-F/ITS-R) ${ }^{49}$ and cox 1 genes $(\mathrm{SF} 1 / \mathrm{SR} 10)^{50,51}$; all these primers worked properly. The PCR mixture $(20 \mu 1$ of reaction mixture and $5 \mu 1$ of DNA extract) comprising of GoTaq ${ }^{\circledR}$ G2 Green Master Mix (Promega, Madison, Wisconsin, USA), 0.4 $\mu \mathrm{M}$ of each primer, DNA template and nuclease-free water to obtain a final volume of $25 \mu \mathrm{l}$. PCR conditions consisted of initial denaturation at $95^{\circ} \mathrm{C}$ for $5 \mathrm{~min}$, followed by 35 cycles of $95^{\circ} \mathrm{C}$ for $30 \mathrm{~s}, 52-60{ }^{\circ} \mathrm{C}$ for $30 \mathrm{~s}, 72{ }^{\circ} \mathrm{C}$ for $1 \mathrm{~min}$, and then a final extension step at $72{ }^{\circ} \mathrm{C}$ for $10 \mathrm{~min}$. The amplification products were resolved on $1.5 \%$ agarose gels and visualized by ethidium bromide staining. The PCR products were purified using the ExoSAP-IT ${ }^{\mathrm{TM}}$ Express PCR Product Cleanup Reagent kit (Thermo Fisher Scientific) according to the manufacturer's protocol. Purified PCR products were directly sequenced in both forward and reverse directions using the same primers as for PCR through the commercial company Eurofins Genomics (Ebersberg, Germany).

Representative nucleotide sequences of $18 S$ rRNA, $28 S$ rRNA, ITS1 and cox 1 loci of $S$. funereus sp. nov. have been deposited in GenBank under the accession numbers MW349706, MW349707, MW373964, MW489293, respectively. Sequences from both forward and reverse strands were assembled and manually edited using FinchTV software (Geospiza Inc., Seattle, Washington) followed by BLAST (Basic Local Alignment Search Tool) program at the NCBI (National Center for Biotechnology Information) server, searches were conducted on obtained sequences for genus/species identification. Sequence chromatograms obtained in this study were aligned using MAFFT software version $7^{52}$.

Phylogenetic trees for all datasets were generated form nucleotide sequences of the selected Sarcocystis species using the MEGA $\mathrm{X}^{53}$ and reconstructed by using the Neighbor-Joining (NJ) and Maximum Likelihood (ML) methods. A NJ phylogenetic tree for $18 S$ rRNA gene (dataset with 25 nucleotide sequences with a total of 1644 aligned nucleotide positions) was computed according to the Tamura-Nei model with a gamma distribution $(\mathrm{TN} 93+\mathrm{G})$. Other phylogenetic trees were generated using ML analyses based on the Kimura 2-parameter model with a gamma distribution 
284

285

rate and a proportion of invariant sites $(\mathrm{K} 2+\mathrm{G}+\mathrm{I})$ for $28 S$ rRNA gene (25 sequences with 1442 positions); for coxl gene (18 sequences with 1013 positions) the Hasegawa-Kishino-Yano model with a gamma distribution $(\mathrm{HKY}+\mathrm{G})$ was used, while the Tamura-Nei model with a gamma distribution rate and a proportion of invariant sites (TN93+G+I) was used for ITS1 region (24 sequences with 1426 positions). All four phylogenetic trees were rooted using Toxoplasma gondii sequence. Consensus trees were obtained after bootstrap analysis with 1000 replications.

\section{Ethics approval}

Not applicable.

\section{Data availability}

The sequences generated in the present study were submitted to the GenBank database under the accession numbers MW349706, MW349707, MW373964, MW489293.

\section{References}

1. Mikkola, H. Owls of Europe (T \& AD Poyser, 1983).

2. König, C. \& Weick, F. Owls of the world. Second edition (New Haven and London, 2008).

3. Korpimäki, E. On the ecology and biology of Tengmalm's owl (Aegolius funereus) in southern

Ostrobothnia and Soumenselkä, western Finland. Acta Univer Ouluensis, Ser A, Scient Rer Nat 118. 13, 1-84 (1981).

4. Korpimäki, E. \& Hakkarainen, H. The Boreal owl: ecology, behaviour and conservation of a forest-dwelling predator (Cambridge, 2012).

5. Kouba, M., Bartoš, L., Šindeláŕ, J., Št’astný, K. Alloparental care and adoption in Tengmalm's owl (Aegolius funereus). J. Ornithol. 158, 185-191 (2017).

6. Wiesner, J. A new sarcosporidian species of Clethrionomys glareolus inhabiting the owl Aegolius funereus as definitive host. J. Protozool. 27, 72A (1980). 
7. Zuo, Y,-X, Zhang, Y. H, Yie, B. Sarcocystis sinensis sp. nov from water buffalo. Abstracts of

311 the Fifty Symposium of the Chinese Society for Protozoology, 82-83 (1990).

312 8. Zuo, Y.-X. \& Yang, Z.-Q. The validity of Sarcocystis sinensis. Zool. Res. 36, 109-111 (2015).

313 9. Espinosa, R., Sterner, M., Blixt, J. \& Cawthorn, R. Description of a species of Sarcocystis

314 (Apicomplexa: Sarcocystidae), a parasite of the northern saw-whet owl, Aegolius acadicus, and

315 experimental transmission to deer mice Peromyscus maniculatus. Can. J. Zool. 66, 2118-2121

316 (1988).

317 10. Černá, Ž. Relationship of oocysts of Isospora buteonis from the barn-owl (Tyto alba) to muscle 318 cysts of sarcosporidians from the house mouse (Mus musadus). Folia Parasitol. 23, 285 (1976).

319 11. Munday, B. L. A species of Sarcocystis using owls as definitive hosts. J. Wildlife Dis. 13, 205$320207(1977)$.

321 12. Černá, Ž., Kolařova, I. \& Šulc, P. Contribution to the problem of cyst-producing coccidians. 322 Folia Parasitol. 25, 9-16 (1978).

323 13. Munday, B. L., Hartley, W. J., Harrigan, K. E., Presidente, P. J. A. \& Obendorf, D. L.

324 Sarcocystis and related organisms in Australian wildlife: II. Survey findings in birds, reptiles, 325 amphibians and fish. J. Wildlife Dis. 15, 57-73 (1979).

326 14. Cawthorn, R. J., Gajadhar, A. A. \& Brooks, R. J. Description of Sarcocystis rauschorum sp. n.

327 (Protozoa: Sarcocystidae) with experimental cyclic transmission between varying lemmings

328 (Dicrostonyx richardsoni) and snowy owls (Nyctea scandiaca). Can. J. Zool. 62, 217-225 (1984).

329 15. Dubey, J. P., Calero-Bernal, R., Rosenthal, B. M., Speer, C. A. \& Fayer, R. Sarcocystosis of 330 Animals and Humans (CRC Press, 2016).

331 16. Levine, N. D. Recent advances in classification of Protozoa. In: Romberger JA, editor.

332 Biosystematics in Agriculture (Beltsville Symposia in Agricultural Research, 2), 71-87 (1978).

333 17. Levine, N. D. \& Tadros, W. Named species and hosts of Sarcocystis (Protozoa: Apicomplexa:

334 Sarcocystidae). Syst. Parasitol. 2, 41-59 (1980). 
18. Verma, S. K. et al. Sarcocystis strixi n. sp. from a barred owl (Strix varia) definitive host and

336 interferon gamma gene knockout mice as experimental intermediate host. J. Parasitol. 103, 768-777

337 (2017).

338 19. Hoberg, E. P., Cawthorn, R. J. \& Hedstrom, O. R. Enteric coccidia (Apicomplexa) in the small

339 intestine of the northern spotted owl (Strix occidentalis caurina). J. Wildlife Dis. 29, 495-497

340 (1993).

341 20. Wünschmann, A., Rejmanek, D., Cruz-Martinez, L. \& Barr, B. C. Sarcocystis

342 falcatula-associated encephalitis in a free-ranging great horned owl (Bubo virginianus). J. Vet.

343 Diagn. Invest. 21, 283-287 (2009).

344 21. Krone, O., Rudolphi, M. \& Jakob, W. Protozoa in the breast muscle of raptors in Germany. Acta

345 Protozool. 39, 35-42 (2000).

346 22. Doležel, D. et al. Phylogenetic analysis of Sarcocystis spp. of mammals and reptiles supports

347 the coevolution of Sarcocystis spp. with their final hosts. Int. J. Parasitol. 29, 795-798 (1999).

348 23. Prakas, P., Butkauskas, D., Švažas, S., Juozaitytė-Ngugu, E., Stanevičius, V. Morphologic and 349 genetic identifcation of Sarcocystis fulicae n. sp. (Apicomplexa: Sarcocystidae) from the Eurasian $350 \operatorname{coot}$ (Fulica atra). J. Wildlife Dis. 54, 765-771 (2018).

351 24. Pan, J. et al. Morphological and molecular characterization of Sarcocystis wenzeli in chickens

352 (Gallus gallus) in China. Parasite Vector. 13, 512-518 (2020).

353 25. Máca, O. \& González-Solís, D. Sarcocystis cristata sp. nov. (Apicomplexa, Sarcocystidae) in 354 the imported great blue turaco Corythaeola cristata (Aves, Musophagidae). Parasite Vector. 14, 1-7 355 (2021).

356 26. Korpimäki, E. Diet of breeding Tengmalm's owls Aegolius funereus: long term changes and 357 year to year variation under cyclic food conditions. Ornis Fennica. 65, 21-30 (1988).

358 27. Hanski, I., Hansson, L., Henttonen, H. Specialist predators, generalist predators, and the 359 microtine rodent cycle. J. Anim. Ecol. 60, 353-367 (1991). 
28. Huitu, O., Norrdahl, K., Korpimäki, E. Landscape effects on temporal and spatial properties of vole population fluctuations. Oecologia. 135, 209-220 (2003).

29. Korpimäki, E., Norrdahl, K., Huitu, O. \& Klemola, T. Predator-induced synchrony in population oscillations of co-existing small mammal species. P. Roy. Soc. B-Biol. Sci. 272, 193-202 (2005).

30. Korpela, K. et al. Non-linear effects of climate on boreal rodent dynamics: mild winters do not negate high-amplitude cycles. Global Change Biol. 19, 697-710 (2013).

31. Kouba, M., Bartoš, L., Bartošová, J., Hongisto, K., Korpimäki, E. Interactive influences of fluctuations of main food resources and climate change on long-term population decline of Tengmalm's owls in the boreal forest. Sci. Report. 10, 1-14 (2020).

32. Šebek, Z. Parasitische Gewebeprotozoen der wildlebenden Kleinsäuger in der Tschechoslovakei. Folia Parasitol. 22, 111-124 (1975).

33. Arnastauskiené, T., Grikieniené, J.. Infection of small mammals with sarcosporidians in the South-Eastern Baltic region. Ecology. 2, 47-56 (1993) (in Russian).

34. Grikienienè, J. \& Mažeikytè, R. Investigation of sarcosporidians (Sarcocystis) of small mammals in Kamasta Landscape Reserve and its surroundings. Acta Zool. Lituanica. 10, 55-68 (2000).

35. Matuschka, F. R. Sarcocystis clethrionomyelaphis n. sp. from snakes of the genus Elaphe and different voles of the family Arvicolidae. J. Parasitol. 72, 226-231 (1986).

36. Mehlhorn, H., Matuschka, F. R. Ultrastructural studies of the development of Sarcocystis clethrionomyelaphis within its final and intermediate hosts. Protistologica. 22, 97-104 (1986).

37. Wilson, T. M. et al. An undescribed species of Sarcocystis associated with necrotizing meningoencephalitis in naturally infected backyard chickens in the Midwest of Brazil. Parasitol Int. 76, 102098 (2020). 
38. Gjerde, B., Vikøren, T. \& Hamnes, I. S. Molecular identification of Sarcocystis halieti n. sp., Sarcocystis lari and Sarcocystis truncata in the intestine of a white-tailed sea eagle (Haliaeetus albicilla) in Norway. Int. J. Parasitol.: Parasites Wildlife. 7, 1-11 (2018).

39. Korpimäki, E., Lagerström, M. \& Saurola, P. Field evidence for nomadism in Tengmalm's owl Aegolius funereus. Ornis Scand. 18, 1-4 (1987).

40. Saurola, P. Natal dispersal distances of Finnish owls: results from ringing. In: Newton I, Kavanagh R, Olsen J, Taylor I, editors. Ecology and Conservation of Owls. CSIRO Publishing, Collingwood, Australia, 42-55 (2002).

41. Kouba, M., Bartoš, L. \& Št’astný, K. Differential movement patterns of juvenile Tengmalm’s owls (Aegolius funereus) during the post-fledging dependence period in two years with contrasting prey abundance. PLoS One. 8, e67034 (2013).

42. Kouba, M., Bartoš, L. \& Št’astný, K. Factors affecting vocalization in Tengmalm's owl (Aegolius funereus) fledglings during post-fledging dependence period: scramble competition or honest signalling of need? PLoS One. 9, e95594 (2014).

43. Svobodová, M. Heteroxenous coccidia of raptors and owls from the Czech and Slovak Republics. Buteo. 9, 35-42 (1997).

44. Korpimäki, E. Highlights from a long-term study of Tengmalm's owls: cyclic fluctuations in vole abundance govern mating systems, population dynamics and demography. Brit. Birds. 113, 316-333 (2020).

45. Barta, J. R. et al. Phylogenetic relationships among eight Eimeria species infecting domestic fowl inferred using complete small subunit ribosomal DNA sequences. J. Parasitol. 83, 262-271 (1997).

46. Fischer, S. \& Odening, K. Characterization of bovine Sarcocystis species by analysis of their 18S ribosomal DNA sequences. J. Parasitol. 84, 50-54 (1998).

47. Gjerde, B. Morphological and molecular characteristics of four Sarcocystis spp. in Canadian moose (Alces alces), including Sarcocystis taeniata n. sp. Parasitol. Res. 113, 1591-1604 (2014). 
48. Dubey, J. P. et al. Sarcocystis caninum and Sarcocystis svanai n. spp. (Apicomplexa:

411 Sarcocystidae) associated with severe myositis and hepatitis in the domestic dog (Canis familiaris).

412 J. Eukaryot. Microbiol. 62, 307-317 (2015).

413 49. Kutkienè, L., Prakas, P., Sruoga, A. \& Butkauskas, D. The mallard duck (Anas platyrhynchos)

414 as intermediate host for Sarcocystis wobeseri sp. nov. from the barnacle goose (Branta leucopsis).

415 Parasitol. Res. 107, 879-888 (2010).

416 50. Gjerde, B. Phylogenetic relationships among Sarcocystis species in cervids, cattle and sheep

417 inferred from the mitochondrial cytochrome c oxidase subunit I gene. Int. J. Parasitol. 43, 579-591

418 (2013).

419 51. Gjerde, B. Sarcocystis species in red deer revisited: with a re-description of two known species

420 as Sarcocystis elongata n. sp. and Sarcocystis truncata n. sp. based on mitochondrial cox1

421 sequences. Parasitology. 141, 441-452 (2014).

422 52. Katoh, K. \& Standley, D. M. MAFFT multiple sequence alignment software version 7:

423 improvements in performance and usability. Mol. Biol. Evol. 30, 772-780 (2013).

424 53. Kumar, S., Stecher, G., Li, M., Knyaz, C., Tamura, K. MEGA X: Molecular evolutionary

425 genetics analysis across computing platforms. Mol. Biol. Evol. 35, 1547-1549 (2018).

426

427 Acknowledgements

428 The authors thank to all colleagues from Laboratory of Parasitology (SVI Prague), especially E.

429 Dubská. Thank are also to T. Bušina and K. Hongisto for their great help during the field work in

430 Kauhava study area, as well as O. Doskočil for making the graphical abstract. This research was

431 performed within the Centre for Infectious Animal Diseases. Succumbed fledglings of Tengmalm's

432 owls were collected, preserved and transported to State Veterinary Institute Prague, Czech Republic

433 under the permission obtained from the Centre for Economic Development, Transport and the

434 Environment in Southwest Finland (permit number VARELY/5933/2019 to Erkki Korpimäki). 


\section{Funding}

437 Open access funding was provided by the Faculty of Agrobiology, Food and Natural Resources,

438 Czech University of Life Sciences Prague. The research project of owls in the Kauhava region was

439 financially supported by the grant provided by the Regional Fund of the South Ostrobothnia of the

440 Finnish Cultural Foundation.

441

442 Author information

443 Affiliations

$444{ }^{1}$ Department of Pathology and Parasitology, State Veterinary Institute Prague, Prague, Czech 445 Republic

$446{ }^{2}$ Department of Zoology and Fisheries, Faculty of Agrobiology, Food and Natural Resources, 447 Czech University of Life Sciences Prague, Prague, Czech Republic

448 Ondřej Máca

449

$450 \quad{ }^{3}$ Department of Ethology and Companion Animal Science, Faculty of Agrobiology, Food and

451 Natural Resources, Czech University of Life Sciences Prague, Prague, Czech Republic

452 Marek Kouba

453

$454{ }^{4}$ Section of Ecology, Department of Biology, University of Turku, Turku, Finland

455 Erkki Korpimäki

456

$457 \quad 5^{*}$ El Colegio de la Frontera Sur, Chetumal, Quintana Roo, Mexico

458 David González-Solís

459

460 Contributions 
461 O.M. conceived and designed the study, M.K. and E.K. conducted field research/collection, O.M.

462 performed laboratory analyses and analyzed data, O.M., D.G.S., wrote the main manuscript. All

463 authors read and approved the final manuscript.

464

465 Corresponding author

466 Correspondence to David González-Solís (dgonzale@ecosur.mx)

467

468 Ethic declarations

469 Competing interests

470 The authors declare no competing interests.

471

472 ARRIVE guidelines

473 This survey was carried out in compliance with the ARRIVE guidelines.

474

$475 \quad$ Figure legends

476 Figure 1 Sarcocystis funereus sp. nov. from Aegolius funereus, light micrographs of oocyst (a) and 477 numerous sporocysts (b) in intestinal mucosa. Arrow indicates thin oocyst wall

478

479 Figure 2 Phylogenetic trees of the species of Sarcocystis from various hosts based on sequences of $48018 S$ rRNA (a), 28S rRNA (b), ITS1 (c) and cox 1 (d) loci. The numbers on phylogenetic trees

481 represent bootstrap values based on 1000 replications. Genbank accession numbers follow

482 Sarcocystis taxa

483

484

485 
486 Figure 1

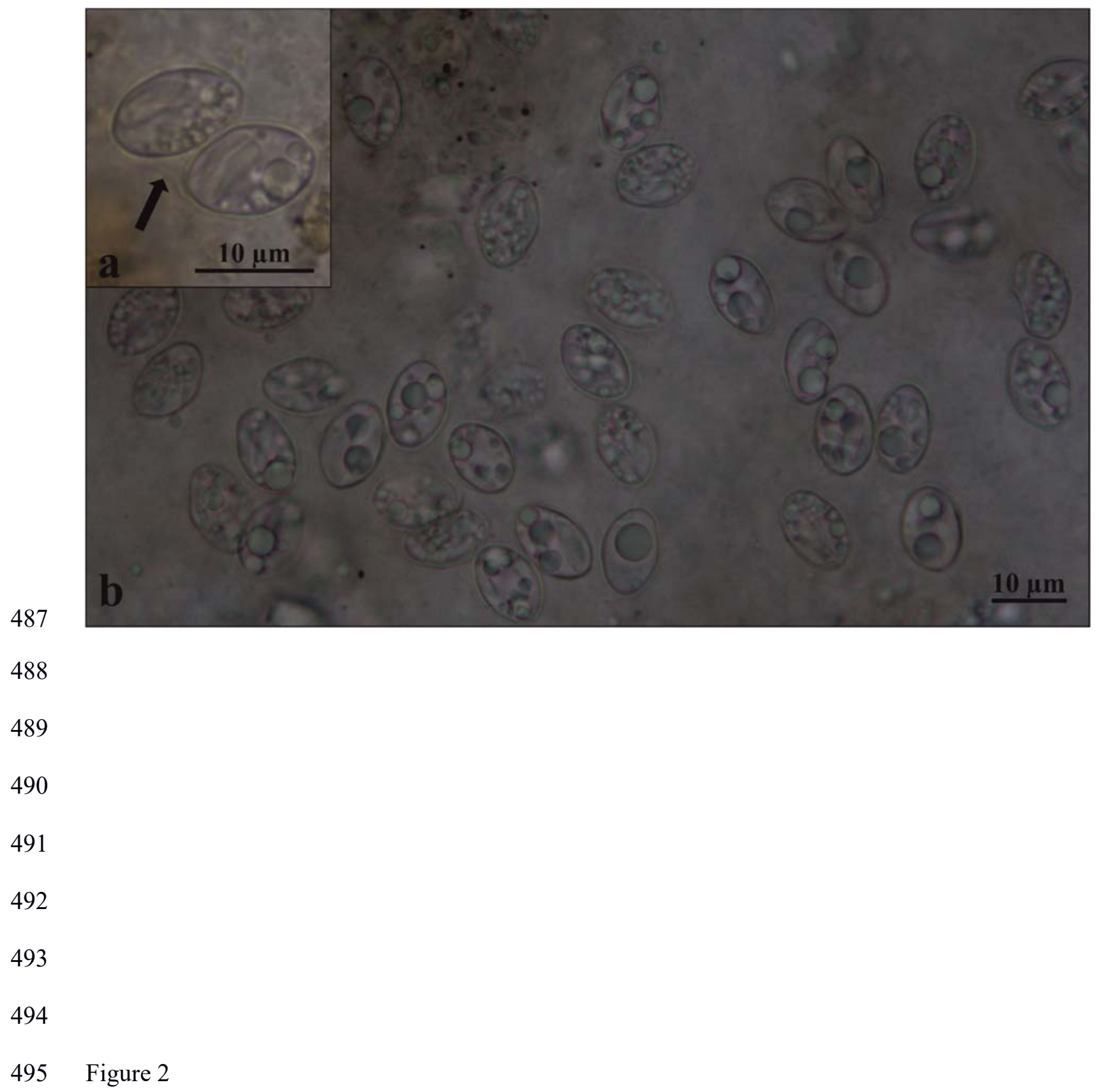


a

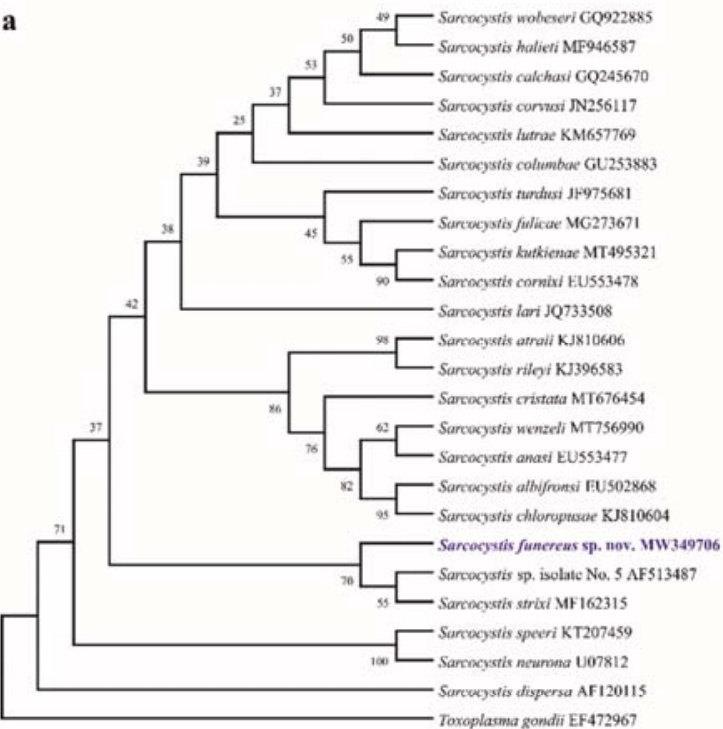

496 c

- Sarcocystis columbae GU253885 - Sarcocostis halieti MF946589

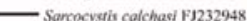
Scukystis wobeseri N256121 Sareocystis fiulicae MG273673

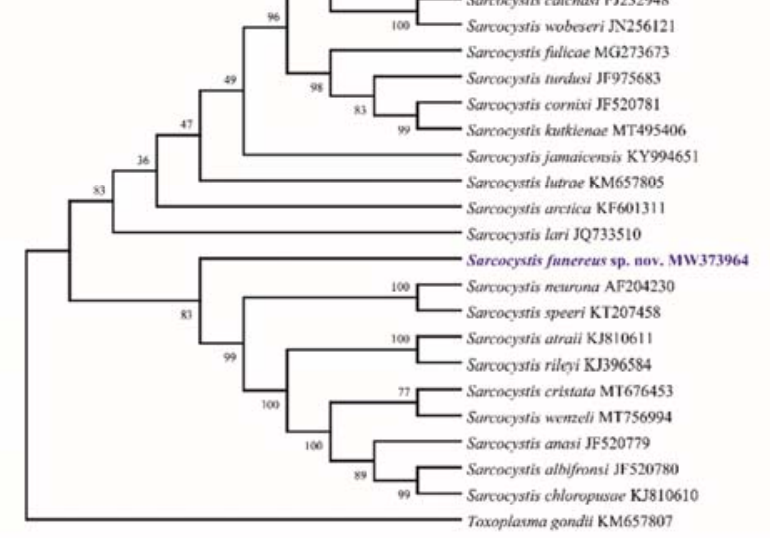

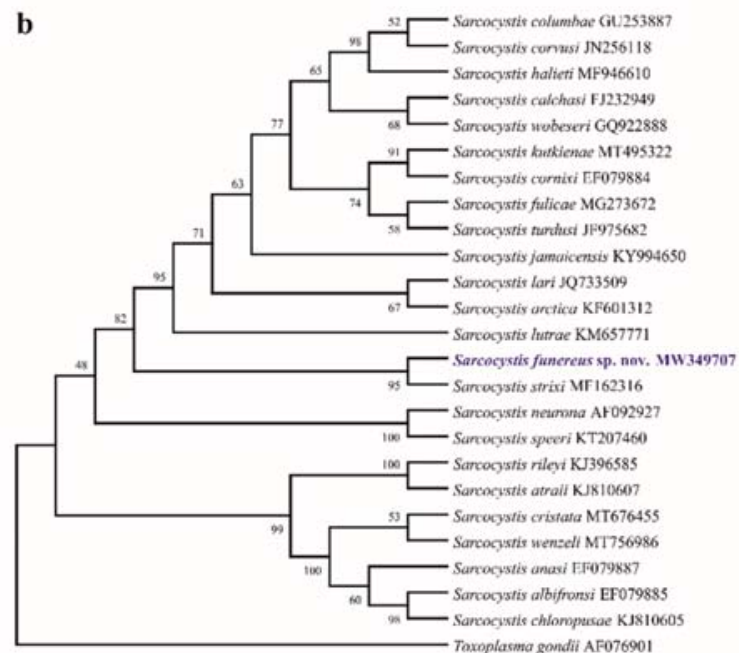

b - Taxoplasma gondii AF076901

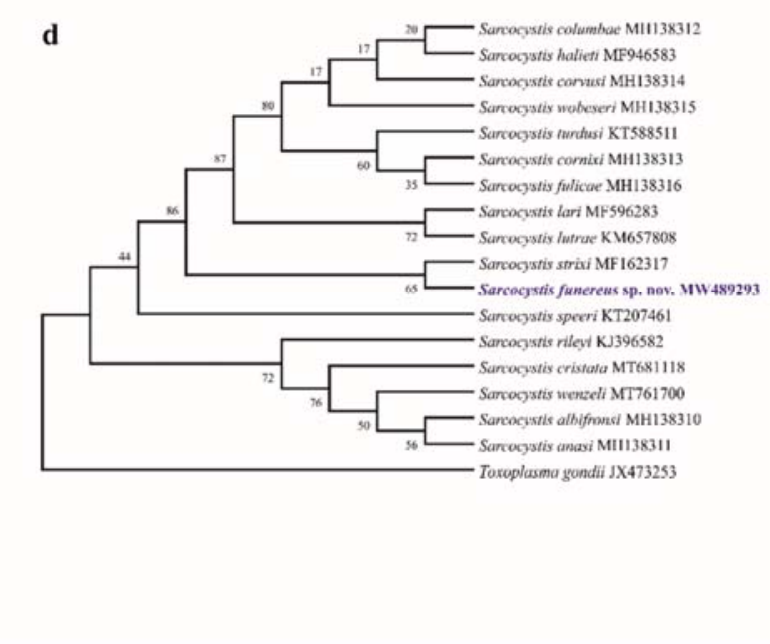

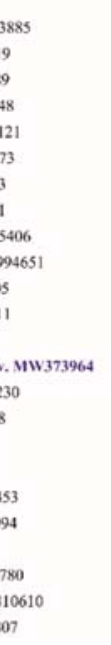

